\title{
$\angle$ Research Soure \\ Reasons for Delayed Pain Management in Patients With Chronic Migraine: A Qualitative Study
}

\section{Marie Susanne Persson ( $\nabla$ marie.s.persson@vgregion.se )}

Primary Health Care Center https://orcid.org/0000-0002-5650-2160

\section{Sandra Weineland}

Primary Health Care Institute

\section{Ronny Gunnarsson}

University of Gothenburg Institute of Medicine: Goteborgs universitet Institutionen for medicin

\section{Eva-Lisa Petersson}

Primary Health Care Institute

\section{Gun Rembeck}

Primary Health Care Institute

\section{Research article}

Keywords: Migraine disorders, chronic pain, pain management, applied behaviour analysis, qualitative research, acceptance

Posted Date: February 8th, 2021

DOI: https://doi.org/10.21203/rs.3.rs-168501/v1

License: (c) (i) This work is licensed under a Creative Commons Attribution 4.0 International License.

Read Full License 


\section{Abstract}

Background: Chronic migraine is often perceived as complex disease and difficult to manage. People with episodic migraine run the risk of developing chronic migraine, leading to great suffering for themselves, their families, and the larger society. The management of each attack may influence the development from episodic to chronic migraine.

Aim: The aim of the present study was to explore experiences and management of migraine pain in patients with chronic migraine.

Methods: Ten migraine patients participated in open interviews based on functional behavioural analysis within a cognitive behavioural framework. The interviews were analysed using systematic text condensation.

Results: Participants' experiences and management of chronic migraine pain was categorized under four concepts: Migraine pain signal, Hope of false alarm, Guiding assumption, and Delayed medical management.

Conclusions: Difficulty distinguishing early migraine pain from other pain signals, neglect of migraine pain signals, and assumption of pain management can lead to delays in initiating emergency medication. Potentially early response to migraine pain signals could alleviate attacks.

\section{Introduction}

Approximately $2.5 \%$ to $3.1 \%$ of patients with episodic migraine annually develop chronic migraine [1], leading to great suffering for patients, their families, and the broader society [2]. An estimated that $1 \%$ to $2 \%$ of the population currently suffer from chronic migraine [3].

\section{Transformation from episodic to chronic migraine}

Prolonged exposure to pain alters the way the brain process information [4]. A long-term effect of recurrent episodes of pain can be the development of chronic pain [5]. In chronic pain, brain structures generate pain in themselves like a signature. Hence, unlike acute pain, chronic pain is not a signal to protect the individual from danger, but rather a symptom of a dysfunctional pain system [4]. Both chronic migraine and acute migraine attacks feature cutaneous allodynia, considered a clinical marker of centralized sensitization of the pain system, which is in turn considered one of the causes of chronic migraine $[6,7]$.

A patient's progression from episodic to chronic migraine is a process that occurs over time, and a central part of this process is learning how to manage pain. Psychosocial maintenance factors such as experiences, thoughts, perceptions and feelings about pain strengthen to some extent and affect how the patient manage their pain $[5,8,9]$. Fear avoidance, usually a management mechanism, is considered an important factor in continuing, and eventually increasing, muscular pain [5]. 
A main symptom, and for patients the most difficult part, of migraine is pain [10]. Patients therefore often develop a pattern of fear avoidance [11], generally defined as attempts to avoid anything believed to trigger pain [5]. An unfortunate consequence of dysfunctional fear avoidance, however, is abstention from behaviours important to the prevention of new migraine attacks. Thus pain avoidance can work against preventing migraine pain and result in a poorer quality of life, unhappiness, and depression.

Depression is an additional stressor that reinforces pain and makes it more difficult to endure both pain and life in general [5]. Quantitative studies have shown an association between migraine, depression, and anxiety, but the direction of causality is not yet established $[12,13]$.

It can also be difficult for people with chronic migraine to exercise when strenuous physical activity is a well-known trigger of migraine attacks. Hence, avoiding regular physical exercise is a common fear avoidance behaviour in patients with migraine [14].

\section{Medication}

Severe cases of chronic migraine can lead to overuse of acute medication and lead to addiction [15]. Development of chronic migraine is assumed to depend partly on the overuse of emergency medication [16]. Although previous qualitative studies show that access to effective pain medication provides patients a sense of security that allows them to live as normally as possible, they also point out patients' fears of side effects and risk of addiction [17].

\section{Acceptance}

Acceptance of pain is reflected in the behaviour patterns of people who engage in, and value, life even in the face of pain. Engaging in valued activities ('value-based action') correlates with less experience of pain, disability, and depression [18].

\section{The remaining challenge}

Pain management is likely to influence the risk of developing chronic migraine, but it is not yet fully understood. The aim of the present qualitative study was to explore chronic migraine patients' experiences and management of pain during a migraine attack.

\section{Method}

Patients with chronic migraine participated in a qualitative interview study exploring their experiences of pain management.

Selection of participants 
Patients with chronic migraine at a neurological outpatient clinic in the Region Västra Götaland in the south-western part of Sweden were asked to take part in a qualitative interview study about pain management in chronic migraines. Seventeen patients who agreed to participate were asked to answer questions about the study's inclusion criteria by mail or telephone. To obtain a strategic selection with a range of variation in participants, the following criteria were considered: rural/urban residency, relationship status, children at home (yes or no), educational level, employment status, and age. People with malignant disease, severe psychiatric problems such as mental illness, drug abuse, and personality disorders, or inability to speak or understand the Swedish language were not included in this study.

Fifteen participants answered the initial questions. From these, the interviewer strategically chose ten to contact with further information about the study and a letter of consent to sign. Inclusion and interviews took place from May to December, 2015.

\section{Data collection}

Data were collected in open interviews based on a functional behavioural analysis. Functional behavioural analysis is part of an applied behaviour analysis in a cognitive behavioural therapy used to map experiences, behaviours, and the short- and long-term consequences of behaviours $[5,19]$.

After a short introduction, the interview typically started with a question like 'Can you tell me about a typical situation when you had a migraine attack?' Participants were encouraged to talk freely with prompts such as 'Can you tell me more?' and 'How did it feel?' Unless already discussed, participants were also asked; 'What were the circumstances?' 'What were the first signs of a migraine attack?' 'What then happened to you (thoughts, emotions, and physiological reactions)?' 'How did you manage pain?' and 'What short- and long-term consequences did this lead to?'

The interviewer's goal, based on functional behavioural analysis [19], was to encourage participants to use their own words. Internal validity was ensured by the interviewer by repeatedly asking participants if they understood and summing up the conversations during and towards the end of the interview. The interviews were conducted by one of the authors (MP), who had no relationship with the participants. Nine interviews took place in a room at the neurology outpatient clinic, and one in the participant's home. The interviews were conducted individually, lasted for 1 to 1.5 hours, and were recorded and transcribed by the interviewer. Participants were offered a travel allowance.

\section{Analysis}

The interviews were analysed using systematic text condensation according to Malterud [20]. The interviewer's preconceptions were those of a clinical cognitive behavioural psychologist/ psychotherapist. The analysis was conducted in four phases. In Phase 1, the texts were read to gain an overall impression of data related to the purpose of the study. Phase 2 involved identifying meaningful units and encoding them. In Phase 3, the content of each code group was sorted into sub-codes. In Phase 4, we created a content description and concept for each code group [20]. 


\section{Results}

Six women and four men between the ages of 18 and 65 , diagnosed with chronic migraine according to the $2 \mathrm{nd}$ revised edition of the International Headache Society Diagnostic Criteria [21], were included in the study. The duration of chronic migraine averaged 11 years. All participants had some form of preventive medicinal treatment: 4 medicated with triptans during the typical migraine attack, 3 medicated step-wise, often starting with a non-prescription drug before proceeding to any form of Triptan, and 3 medicated with a non-prescription drug during the attack.

\section{Table 1.}

Demographic characteristics of participants $(\mathrm{N}=10)$ 


\begin{tabular}{|c|c|}
\hline Age, median (min-max) & 49 years $(28-65)$ \\
\hline \multicolumn{2}{|l|}{ Gender } \\
\hline Women $(n=6)$ & 49 years $(28-65)$ \\
\hline Men $(n=4)$ & 50 years $(29-65)$ \\
\hline \multicolumn{2}{|l|}{ Use of emergency medicine } \\
\hline Triptan & 4 \\
\hline Prescription-free & 3 \\
\hline Both (staircase model*) & 3 \\
\hline \multicolumn{2}{|l|}{ Relationship status } \\
\hline Married & 4 \\
\hline Live-in partner & 3 \\
\hline Divorced & 2 \\
\hline Single & 1 \\
\hline Children at home & 5 \\
\hline No children at home & 5 \\
\hline \multicolumn{2}{|l|}{ Highest education } \\
\hline Upper-secondary & 4 \\
\hline College/university & 6 \\
\hline \multicolumn{2}{|l|}{ Employment } \\
\hline Employed & 4 \\
\hline Unemployed & 1 \\
\hline On sick leave/pension & 5 \\
\hline \multicolumn{2}{|l|}{ Occupation } \\
\hline Teacher & 2 \\
\hline Professional in health or social sector & 5 \\
\hline Artist & 1 \\
\hline Blue collar worker & 2 \\
\hline Live in urban area & 7 \\
\hline Live in rural area & 3 \\
\hline
\end{tabular}


*In the staircase model, participants are medicated step-by-step, often starting with a non-prescription drug before going on to some form of Triptan if the first measure proves insufficient.

\section{Main categories}

The participants' experience and pain management strategies were assigned to one or more of four concepts: Migraine pain signal, Hope of false alarm, Guiding assumption, and Delayed medical management.

Migraine pain signal

Participants first experienced the migraine pain signal as either a progressive development during the day or acute pain upon waking early in the morning. Pain behind the eye, on the temple, or on the side of the head was generally interpreted as a signal that 'now the migraine begins'. However, participants had difficulty distinguishing between migraine pain signal and other types of head or neck pain.

But when I tell someone, it's very much like this, 'Ah, but take the medicine when you feel it coming on'. But I find that really hard to do. I find it really hard to know... even though I've had migraine for so many years. But knowing that, 'Ah, now is the time to take medication', or 'I can get through the day without medication' I find really difficult... Participant (P) 5

What is it that makes you wait until you have [...] intense pain? Interviewer (I)

I didn't think it was a migraine. (P8)

It's that hard to differentiate? (I)

Mmhm. [Crying]. You know. I haven't gotten so much help with it [Crying]. (P8)

Hope of a false alarm

A common pattern arose in which participants dismissed migraine pain signals until they could no longer be ignored. When the participants interpreted the migraine signal, they hoped it was a false alarm, and decided to wait and try non-medical treatment first. However, when they woke up with migraines, they were more likely to take their medication immediately.

I[...] denied it, but was aware it was there, but felt this did not affect me at the moment. (P5)

... Iittle ignorance that I had... Especially now, when I think back on it, I had a, you know. I had, you know, a headache long before I took the medicine. But it was [...] in any case quite a while, certainly a few hours 
that, I sat with... a headache, and probably could have taken, taken it seriously, and taken medicine at that time. (P4)

\section{Guiding assumption}

A guiding assumption in this context refers to an idea or rule that guides behavioural pain management during a migraine attack. The guiding assumption in the actual situation of emerging pain seemed to be 'If I wait and try something else first, maybe I won't need to take migraine medication'.

There were three reasons why the participants refrained as long as possible from taking emergency medication at the beginning of the migraine attack. The first, a health perspective, includes fear of addiction and/or of taking too much migraine medication, avoiding medication-induced migraine pain or avoid unwanted side effects associated with medication including memory loss and hallucinations. The second, a low-function perspective, comprises thoughts about not being able to drive or work while taking medication, and the third reason were, a popular tradition and internal rules perspective, includes to avoid unnecessary medicine, or first have extreme pain before taking medicine.

I also feel a little like, I don't want to take Imigran like this. It's rather ridiculous to know that you're putting a lot of medicine inside yourself. I wait for it to pass, but that happens perhaps only one time in twenty.

I'm a little afraid of drug abuse. I willingly wait before I take a tablet even when [I'm] in so much pain. (P10)

\section{Delayed medical management}

The guiding assumption, 'If I wait and try something else first, I may not need to take migraine medication', led to delay in medication up to several hours after the first migraine pain signal.

Participants described a variety of inner (mental) strategies to manage pain during the migraine attack: 'trying to put up with it', trying to find a connection or cause, criticizing themselves, and trying to stay calm. The participants' external behaviours during the attack (e.g., drinking water, meditating, or getting some fresh air) were determined by the participant's interpretation of the cause of the migraine attack.

The negative consequences of migraine pain included poor sleep, slow recovery, and much lost time. These consequences impacted participants' families and themselves physically, emotionally, socially, and at work. Participants felt sad and angry about the frequent attacks and the suffering they caused and hopeless about their inability to manage their illness. Some said that during severe attacks the thought they would prefer to die. The stronger the pain, however, the greater its effect on participants' functioning.

How long was it [before taking acute medication] after you felt tightness around the eye? (I)

[Short pause] Four, five hours. About four or five hours. Because then I thought, 'I can manage [the dog], so I can go out'. (P2) 
Did you try to wait out the pain itself? (I)

Yes, I tried it; yes, before I took the injection. And it's very stupid. But I do it. Do it very often, and especially when taking too much medicine, I think, 'Yes, it'll be fine, I'll have a cup of coffee'. (P2)

So, I've had many occasions where the headache has gotten worse because I didn't bother... to take my medicine. When I really should have taken it. If I feel I need medication, and I don't take the medicine, the headache becomes worse. And then I become much more affected by it. (P3)

\section{Discussion}

This study showed that participants had difficulty distinguishing early migraine pain from other types of pain. Even when they interpreted the pain as migraine, most first tried to manage the attack with nonmedical strategies before taking medication. Guiding assumptions of pain management are important for the participants handling the attack.

Migraine pain signal

Consistent with previous studies, despite investments of time and energy, participants had difficulty distinguishing migraine from other pain [22]. Their migraine attacks were frequent, and it could be difficult for them to distinguish what stage of the attack they were in.

Patients who focus on triggers may interpret them incorrectly and reduce their activity, which in the long term can lead to depression and reduced quality of life $[5,19]$. Focusing instead on migraine pain signals can make the discussion of possible triggers unnecessary in chronic migraines [23].

Hope of false alarm

A common pattern of dismissing migraine pain signals caused delays in taking medication, which was usually no longer effective when finally taken. That delay could work in the short term, allowing patients to complete tasks and get to work regularly, thus strengthening them socially and economically. The need to dismiss migraine pain signals can also be partly understood in the fact that after a migraine attack, the patient hopes that there may not be more attacks [22]. 'Hope of false alarm' might be related to the psychological process of experiential avoidance, meaning that the patient avoids accepting what happens [24].

\section{Guiding assumption}

Somewhere perhaps in episodic migraine, it has worked to wait and try non-medical management. The probable learning principle may be intermittent reinforcement [20].

The person with migraine always strives for a high-performance ability [11]. An increased frequency of migraine attacks leads to increased acute intake of medicine which may be one of the causes of the development of chronic migraine [17]. 
Using prescription-free medicines during a migraine attack meant facing the pain inadequately medicated. From a physiological perspective, repeated and continuing pain increases sensitization and makes the pain-relieving system less effective $[4,9]$. Hence, insufficient pain medication may create more pain than it relieves [4]. This contradicts the hypothesis that chronic migraine is due to overuse of acute migraine medication [16].

\section{Delayed medical management}

Participants lack knowledge about how to regulate their use of acute migraine medication. They typically waited to take emergency medication, hoping that the attack would pass or that they could somehow manage without it. By the time they finally took their acute medication when the pain was intense, it could alleviate the pain, but not eliminate it. They were not rid of the pain, but it continued for several days. This may have led to more medication during the attack than if they had chosen to medicate at an earlier stage. How delaying medical management affects the development of chronic migraine in a positive or negative way is at yet unexplored. Participants tended to delay not only prescribed medication, but also other management strategies, such as rest, until the pain became intense.

When in pain, one usually advocates active management, that is, confront and meet the pain without avoidance and control behaviour [5]. In a migraine context, it is perhaps advantageous to confront the pain and accept the emerging situation at an early stage when pain is mild, with emergency medication, and rest as an act of acceptance and self-compassion [25]. Take emergency medicine when the pain is mild has been shown to lead to reduced disability $[26,27]$.This is consistent with pain research that shows that early action prevents the transition from peripheral to central sensitization during the attack [6].

\section{Methodological aspects}

Any interview is limited by the participant's openness, ability to immerse in a situation, recall the situation, and verbalize the experience. Functional behavioural analysis was found to perform well in the interview to map participants' experience and management of pain and encourage them to reflect upon their experiences. A limitation of the study was its exclusion of patients over the age of 65 . It would be interesting to see whether and how chronic migraine develop at later ages, but that was not within the scope of this study.

The choice of interview questions was based on the fact that pain associated with neurological disease follows behavioural and learning principles. The delayed use of acute medicine may have been the result of having many migraine attacks, and the behaviour need not have existed in episodic migraine. Thus, the transferability of the result may be considered limited in terms of risk factors in developing chronic migraine.

\section{Conclusion}


Our main conclusion is that the migraine patients in this study often found it difficult to distinguish migraine pain from other pain, automatically rejected the migraine pain signal, used non-medical management for various reasons and only took their prescribed medication when it was no longer optimally effective, which complicated further management of pain. Future research should investigate whether migraine patients' pain relief strategies differ between those with chronic and episodic migraine.

\section{Declarations}

\section{Ethics approval and consent to participate}

The study was approved by the Regional Ethical Review Board in Gothenburg (Dnr: 821-14). Written informed consent was obtained from all patients.

\section{Consent for publication}

Not applicable

\section{Availability of data and material}

Data and material from this study are available from the corresponding author upon reasonable request.

\section{Competing interests}

There are no conflicts of interest in connection with this study.

\section{Funding}

Local Research and Development Council of Södra Älvsborg [VGFOUSA-424081]

\section{Authors' contributions}

MP conducted the interviews. MP, GR, and ELP analysed and interpreted the interviews according to systematic text condensation. All authors (MP, GR, ELP, SW, and RG) contributed to writing, reading, and approving the final manuscript.

\section{Acknowledgements}

The authors would like to thank the participants who shared their experiences of pain and pain management during a migraine attack.

\section{References}

1. Bigal ME, Serrano D, Buse D, Scher A, Stewart WF, Lipton RB. Acute migraine medications and evolution from episodic to chronic migraine: a longitudinal population-based study. Headache. 2008;48:1157-68. 
2. Ruiz de Velasco I, Gonzalez N, Etxeberria Y, Garcia-Monco JC. Quality of life in migraine patients: a qualitative study. Cephalalgia. 2003;23:892-900.

3. Bigal ME, Serrano D, Reed M, Lipton RB. Chronic migraine in the population: burden, diagnosis, and satisfaction with treatment. Neurology. 2008;71:559-66.

4. Melzack R. Evolution of the neuromatrix theory of pain. The Prithvi Raj Lecture: presented at the third World Congress of World Institute of Pain, Barcelona 2004. Pain Pract. 2005;5:85-94.

5. Linton S. Understanding patients in pain. Student literature; 2005.

6. Burstein R, Cutrer MF, Yarnitsky D. The development of cutaneous allodynia during a migraine attack: clinical evidence for the sequential recruitment of spinal and supraspinal nociceptive neurons in migraine. Brain. 2000;123(Pt 8):1703-9.

7. Louter MA, Bosker JE, van Oosterhout WP, van Zwet EW, Zitman FG, Ferrari MD, et al. Cutaneous allodynia as a predictor of migraine chronification. Brain. 2013;136(Pt 11):3489-96.

8. Gatchel RJ, Peng YB, Peters ML, Fuchs PN, Turk DC. The biopsychosocial approach to chronic pain: scientific advances and future directions. Psychol Bull. 2007;133:581-624.

9. Woolf CJ; American College of Physicians, American Physiological Society. Pain: moving from symptom control toward mechanism-specific pharmacologic management. Ann Intern Med. 2004;140:441-51.

10. Linde $M$, Dahlof $C$. Attitudes and burden of disease among self-considered migraineurs - a nationwide population-based survey in Sweden. Cephalalgia. 2004;24:455-65.

11. Meyer GA. The art of watching out: vigilance in women who have migraine headaches. Qual Health Res. 2002;12:1220-34.

12. Gambini O, Islam L, Demartini B, Scarone S. Psychiatric issues in patients with headaches. Neurol Sci. 2010;31 Suppl 1:S111-3.

13. Bigal ME, Liberman JN, Lipton RB. Obesity and migraine: a population study. Neurology. 2006;66:545-50.

14. Varkey E. On the prevention of migraine - focus on exercise and the patient's perspective. [doctoral thesis]. Sahlgrenska Academy, University of Gothenburg; 2012.

15. Biagianti B, Grazzi L, Usai S, Gambini O. Dependency-like behaviors and pain coping styles in subjects with chronic migraine and medication overuse: results from a 1-year follow-up study. BMC Neurol. 2014;14:181.

16. Meng ID, Dodick D, Ossipov MH, Porreca F. Pathophysiology of medication overuse headache: insights and hypotheses from preclinical studies. Cephalalgia. 2011;31:851-60.

17. Rutberg S, Ohrling K. Migraine - more than a headache: women's experiences of living with migraine. Disabil Rehabil. 2012;34:329-36.

18. Dindo L, Recober A, Marchman J, O'Hara M, Turvey C. Depression and disability in migraine: the role of pain acceptance and values-based action. Int J Behav Med. 2015;22(1):109-17.

19. Eikeseth SS, F. Applied behaviour analaysis. Student literature; 2007. 
20. Malterud K. Systematic text condensation: a strategy for qualitative analysis. Scand J Public Health. 2012;40:795-805.

21. Headache Classification Subcommittee of the International Headache Society. The international classification of headache disorders: 2nd edition. Cephalalgia. 2004;24 Suppl 1:9-160.

22. Peters M, Huijer Abu-Saad H, Vydelingum V, Dowson A, Murphy M. The patients' perceptions of migraine and chronic daily headache: a qualitative study. J Headache Pain. 2005;6:40-7.

23. Olesen J. Highlights in headache research in 2013. Lancet Neurol. 2014;13:5-7.

24. Hayes SC, Luoma JB, Bond FW, Masuda A, Lillis J. Acceptance and commitment therapy: model, processes and outcomes. Behav Res Ther. 2006;44:1-25.

25. Gilbert P. Compassion-focused therapy: preface and introduction for special section. $\mathrm{Br} \mathrm{J}$ Clin Psychol. 2014;53:1-5.

26. Seng EK, Rains JA, Nicholson RA, Lipton RB. Improving medication adherence in migraine treatment. Curr Pain Headache Rep. 2015;19:24.

27. Dahlof C. Cutaneous allodynia and migraine: another view. Curr Pain Headache Rep. 2006;10:231-8.

\section{Figures}

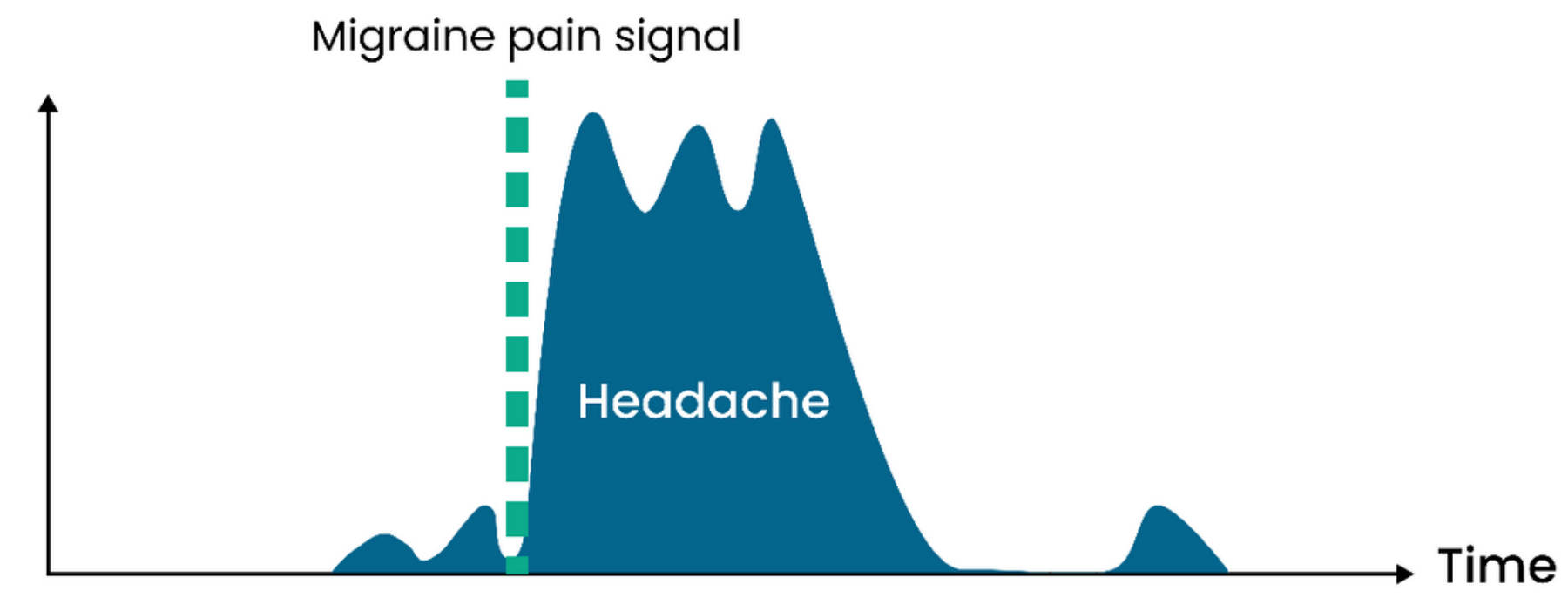

\section{Premonitary Headache Resolution Postdrome phase phase}

\section{Figure 1}

Future research should investigate whether migraine patients' pain relief strategies differ between those with chronic and episodic migraine 